\title{
A Microbial Transformation Model for Simulating Mammal Metabolism of Artemisinin
}

\author{
Yue Ma ${ }^{1,2}$, Peng Sun ${ }^{1,2}$, Yifan Zhao ${ }^{1,2}$, Kun Wang ${ }^{1,2}$, Xiaoqiang Chang ${ }^{1,2}$, Yue Bai ${ }^{1,2}$, \\ Dong Zhang $1,2, * \mathbb{D}$ and Lan Yang $1,2, *$ \\ 1 Institute of Chinese Materia Medica, China Academy of Chinese Medical Sciences, Beijing 100700, China; \\ yuema_2016@126.com (Y.M.); psun@icmm.ac.cn (P.S.); zyfan_666@163.com (Y.Z.); \\ supervipwk@163.com (K.W.); 19937381620@163.com (X.C.); by15076380819@163.com (Y.B.) \\ 2 Artemisinin Research Center, Beijing 100700, China \\ * $\quad$ Correspondence: dzhang@icmm.ac.cn (D.Z.); lyang@icmm.ac.cn (L.Y.); Tel.: +86-10-6408-7947 (D.Z. \& L.Y.) \\ Academic Editors: Carlo Siciliano and Anna Napoli \\ Received: 4 December 2018; Accepted: 8 January 2019; Published: 16 January 2019 \\ check for
}

\begin{abstract}
Artemisinin (ART) is a highly effective antimalarial agent isolated from the traditional Chinese herb Qinghao. Metabolism of ART and its derivatives in the body is one of the most pressing issues for pharmaceutical scientists. Herein, an efficient in vitro microorganism model for simulation of metabolism of ART in vivo was developed employing Cunninghamella elegans. Metabolites in the microbial transformation system and plasma of mice pre-administrated ART orally were analyzed by ultra-performance liquid chromatography (UPLC)-electrospray ionization (ESI)-quadrupole time-of-flight (Q-TOF)-mass spectrometry $\left(\mathrm{MS}^{\mathrm{E}}\right)$ combined with UNIFI software. Thirty-two metabolites were identified in vitro and 23 were identified in vivo. After comparison, 16 products were found to be common to both models including monohydroxylated ART, dihydroxylated ART, deoxyartemisinin, hydroxylated deoxyartemisinin, hydroxylated dihydroartemisinin (DHA), and hydroxylated deoxy-DHA. These results revealed that C. elegans CICC 40250 functioned as an appropriate model to mimic ART metabolism in vivo. Moreover, an overall description of metabolites of ART from C. elegans CICC 40250 has been provided. Notably, DHA was detected and identified as a metabolite of ART in mouse plasma for the first time.
\end{abstract}

Keywords: microbial transformation; Cunninghamella elegans; metabolite; identification; artemisinin; UPLC-ESI-Q-TOF-MS ${ }^{\mathrm{E}}$; UNIFI software; in vivo

\section{Introduction}

Artemisinin (ART), a well-known natural product, was first isolated from the leaves of Aremisia annua Linn by Professor Tu and coworkers in the 1970s [1,2]. Millions of lives threatened by malaria have been saved by this excellent agent in the last decades [3]. Recently, ART was found to exhibit extensive bioactivities such as anti-schistosoma, antitumor, immunosuppression, and antifibrosis [4,5]. Insight of its significant applications in pharmaceuticals and bioactive agents [6] as well as the metabolites of ART in the body are of great interest to researchers.

Due to the rapid and extensive metabolism of ART in the body [7-9], direct study of its metabolites in the body is challenging [10-14]. Significant progresses have been made to predict the drug disposal process, and a series of metabolites have been predicted in previous studies [15-20]. In spite of these brilliant works, the efficient tools to generate abundant metabolites in vitro are still in demand, which could provide the possibility for further bioevaluation and synergistic effect study of the metabolites.

In recent years, microbial transformations have become powerful routes for metabolic simulations [21], and have been used to study metabolism of a variety of clinical drugs, such as 
fenofibrate [22], imipramine [23], monensin A [24], and cinobufagin [25]. Compared with in vivo metabolism studies and microsomal methods, microbial transformation is more convenient and cost-effective, especially with the advantage of scalability in vitro. Over the last few decades, a number of ART metabolites were obtained and identified via several species of fungi [26,27],

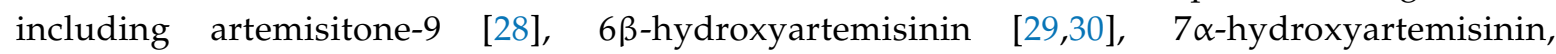
7 $\beta$-hydroxyartemisinin, $7 \beta$-hydroxy- $9 \alpha$-artemisinin [31] $1 \alpha$-hydroxyartemisinin [32], 10ß-hydroxyartemisinin, C-9 acetoxy artemisinin [33], $9 \alpha$-hydroxyartemisinin, deoxyartemisinin [34] $4 \alpha$-hydroxy-1-deoxyartemisinin [35,36], 5 $\alpha$-hydroxyartemisinin [37], artemisinin G, 6ß, 7 $\alpha$-hydroxyartemisinin [38], and 14-hydroxy-deoxyartemisinin [39]. However, whether these compounds were produced in vivo has not been verified.

Herein, to get some insight of ART metabolism and also as parts of our ongoing projects on ART research $[40,41]$, we conducted our study on the metabolism simulation employing of ART employing the fungus Cunninghamella elegans CICC 40250. Divergent metabolites were produced via this microbial model in vitro. Moreover, metabolites in mouse plasma were also identified and compared with the products generated in vitro in our study. This study demonstrated the possibility of obtaining potentially valuable metabolites in large quantities, and a convenient and low-cost microbial model for ART metabolism simulation would help for obtainment of new candidates and exploration of the mechanism of action.

\section{Results}

\subsection{Optimization of Ultra-Performance Liquid Chromatography (UPLC) Conditions}

To improve the resolution and intensities of chromatographic peaks, various compositions of mobile phase (methanol, acetonitrile, and formic acid) were tested to optimize chromatographic conditions. As a result, acetonitrile (containing $0.1 \%$ formic acid) and water (containing $0.1 \%$ formic acid) were used as the mobile phases. The gradient program for samples, which included five segments, was as follows, $5-100 \%$ B from 0 to $15 \mathrm{~min}, 100-5 \%$ B from 15 to $17 \mathrm{~min}$, and a post-run of $3 \mathrm{~min}$ for column equilibration. The flow rate was $0.4 \mathrm{~mL} \mathrm{~min}^{-1}$, and the temperature was held at $25^{\circ} \mathrm{C}$ throughout the period of analysis.

\subsection{Optimization of Sample Preparation}

Protein precipitation (acetonitrile and methanol) and solid-phase extraction (SPE) were evaluated for extraction of metabolites. SPE allowed for simultaneous extraction of all target compounds. Greater amounts of target compounds were obtained using SPE compared with protein precipitation. Moreover, methanol, selected as the elution solvent for SPE, was used at the optimal flow rate of one drop every $3 \mathrm{~s}$. To determine the optimal volume of methanol required to elute target compounds from the SPE cartridge, elution was performed twice with $1.0 \mathrm{~mL}$ methanol each. Our results showed that $1.0 \mathrm{~mL}$ of methanol was sufficient to elute the target compounds. As a result, the optimize elution program of SPE was described as $1.0 \mathrm{~mL}$ of water followed by $1.0 \mathrm{~mL}$ of methanol at the flow rate of one drop every $3 \mathrm{~s}$. The target compounds were gathered in the organic phase.

\subsection{Identification of Reference Substances}

The reference substances ART, deoxyartemisinin (de-ART), and dihydroartemisinin (DHA) were used to establish reference fragmentation patterns. The molecular ions $[\mathrm{M}+\mathrm{H}]^{+},\left[\mathrm{M}+\mathrm{Na}^{+}\right.$, and $[\mathrm{M}+\mathrm{K}]^{+}$of ART in positive mode were observed at $m / z$ 283.1537, 305.1354, and 321.1092, respectively. The fragment ions at $m / z 265,247$, and 229 were generated by successive loss of a water from $m / z 283$, and $m / z 237$ also resulted from loss of $\mathrm{HCOOH}$ from the fragment represented by $m / z$ 283. Moreover, the fragment ion at $m / z 219$ was generated by loss of a water from the fragment represented by $m / z$ 237. In addition, the fragment ion $m / z 209$ was generated from loss of $\mathrm{CHCH}_{3}$ from the $m / z 237$ fragment, which was also the mechanism of transition from $m / z 219$ to $m / z 191$. 
The fragment represented by $m / z 205$ was generated by loss of $\mathrm{CH} 3 \mathrm{COOH}$ from the $m / z 265$ fragment. Mass spectra and the fragmentation scheme for ART are shown in Figure 1A.

The reference substance de-ART showed similar characteristic product ions to ART. The molecular ions were represented by $m / z 267.1589\left([\mathrm{M}+\mathrm{H}]^{+}\right), 289.1407\left([\mathrm{M}+\mathrm{Na}]^{+}\right)$, and $305.1142\left([\mathrm{M}+\mathrm{K}]^{+}\right)$. The fragment ions at $m / z 249,231,221$, and 203 were 16 Da less than the corresponding fragment ions of ART. In addition, the fragment ion at $m / z 239$ was generated from loss of CO from the $m / z 267$ fragment. Compared with ART, the fragments of de-ART were less susceptible to loss of water, but more susceptible to loss of $\mathrm{CO}$. Mass spectra and the fragmentation scheme for de-ART are shown in Figure 1B.

DHA showed molecular ions $[\mathrm{M}+\mathrm{H}]^{+},[\mathrm{M}+\mathrm{Na}]^{+}$, and $[\mathrm{M}+\mathrm{K}]^{+}$at $m / z$ 285.1447, 307.1509, and 323.1251, respectively. Fragments of DHA were similar to those of ART, with $m / z 267,249$, and 231 resulting from successive loss of water from the $m / z 285$ fragment, and $m / z 239$ resulted from $m / z 285$ by loss of $\mathrm{HCOOH}$. The fragment ions at $m / z 221$ and $m / z 203$ resulted from loss of one water and two waters, respectively, from the $m / z 239$ fragment. Mass spectra and the fragmentation scheme for DHA are shown in Figure $1 \mathrm{C}$.

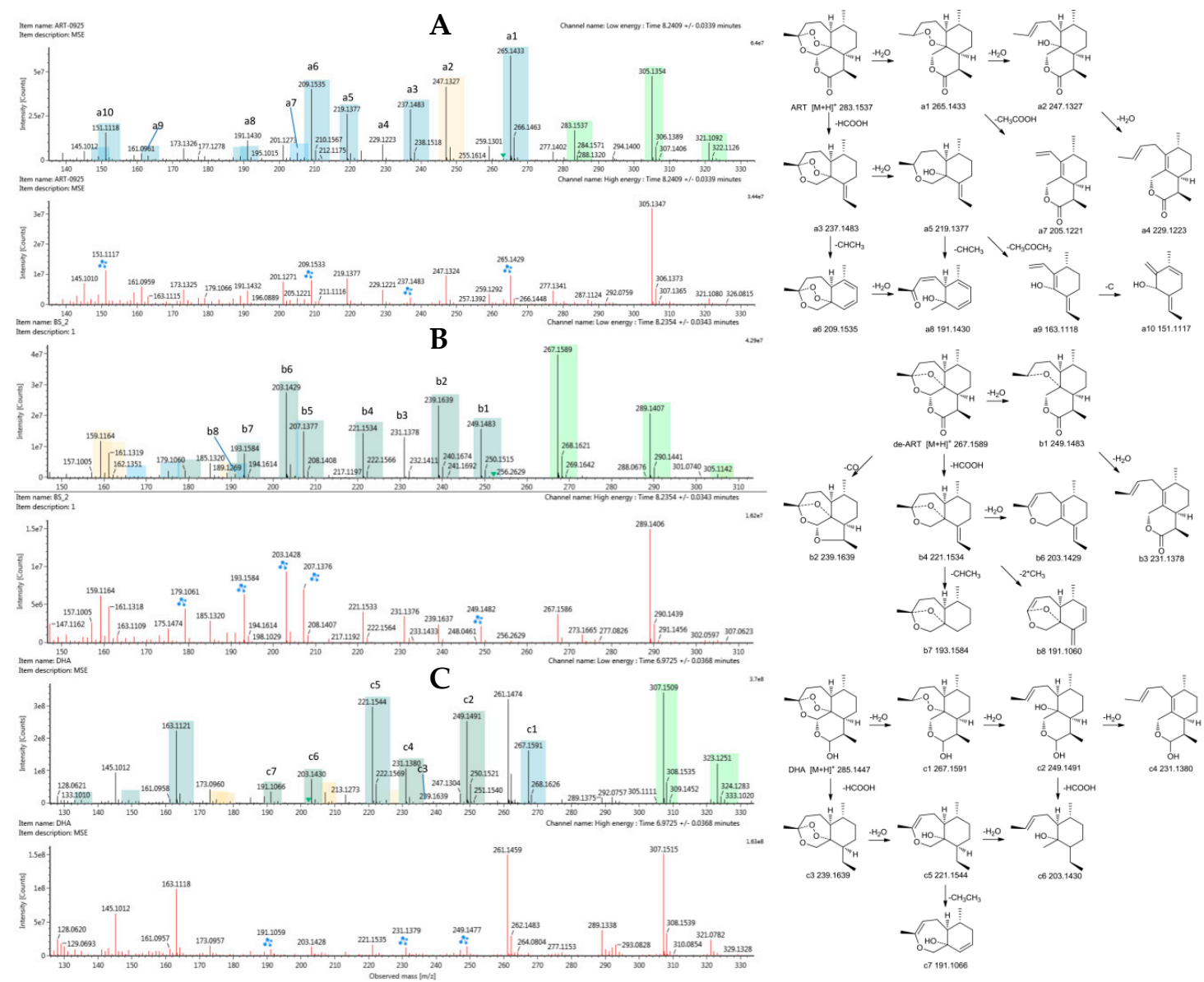

Figure 1. Mass spectrometry $\left(\mathrm{MS}^{\mathrm{E}}\right)$ spectra (A) artemisinin (ART), (B) deoxyartemisinin (de-ART), and (C) dihydroartemisinin (DHA) as well as the proposed fragmentation pathways. A blue box behind the low-energy fragment ions shows in-source fragment ions and a green box indicates adduct clusters.

\subsection{Identification of Metabolites}

To evaluate the ability of microbial transformation models to mimic metabolism in vivo, metabolites in mouse plasma and in a microbial transformation system were evaluated by UPLC-electrospray ionization (ESI)-quadrupole time-of-flight (Q-TOF)-mass spectrometry $\left(\mathrm{MS}^{\mathrm{E}}\right)$ and identified using UNIFI 1.9 software (Waters, Manchester, UK). Analytes in each sample were compared based on characteristic mass spectrometric behavior, including parent ions, internal cleavage in the ion 
source, and characteristic fragment ions of each metabolite, as well as by retention time. Compared with the peaks in the corresponding blank sample, a total of 39 additional peaks were observed and presumed to be metabolites in plasma and the microorganism system. The observed metabolites were generated by monohydroxylation and dihydroxylation of ART, de-ART, hydroxy-de-ART, DHA, hydroxy-DHA, and hydroxy-deoxy-DHA. All metabolites identified were listed in Table 1. Extracted ion chromatograms of the metabolites in plasma and fermentation broth are shown in Figure 2.

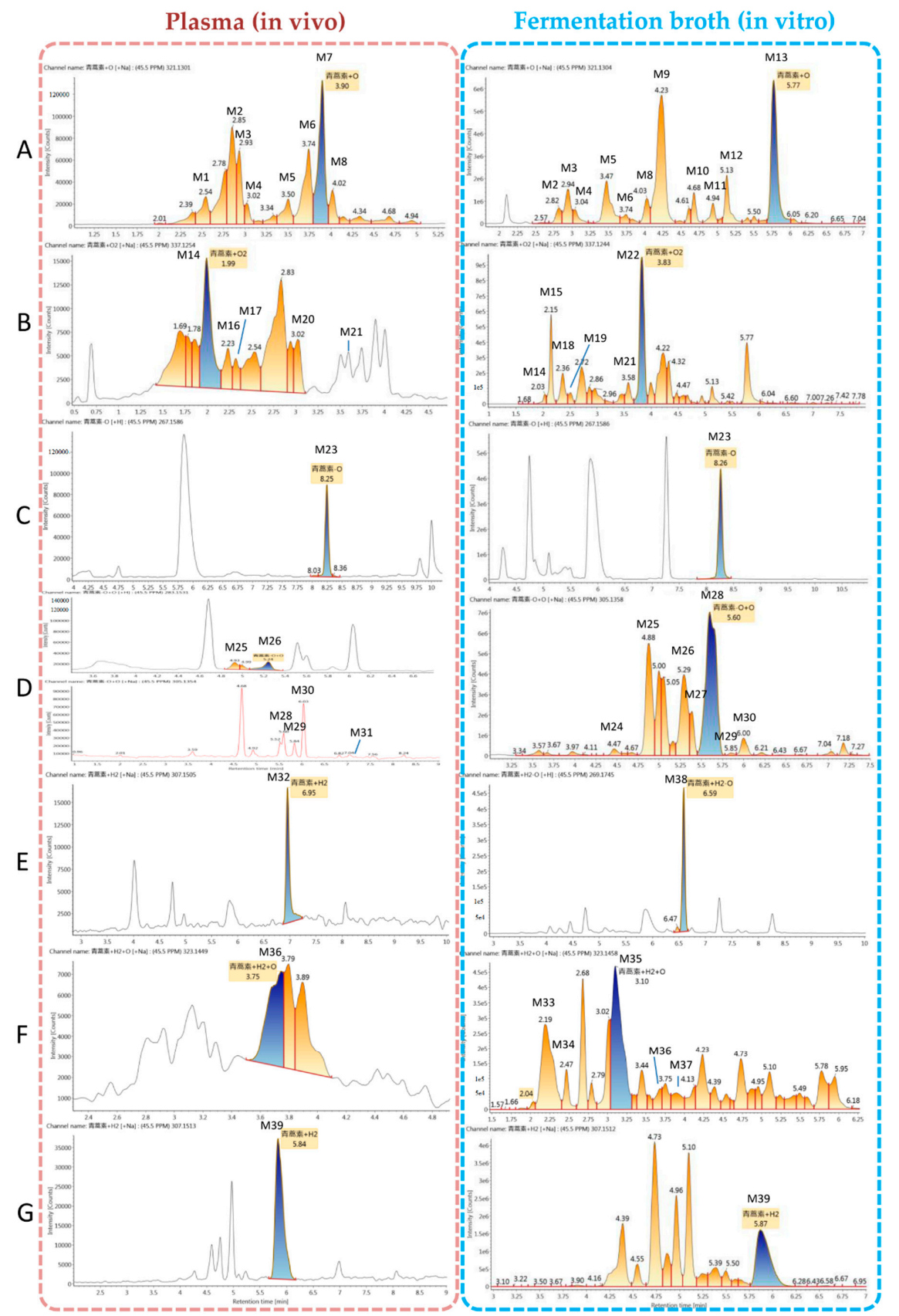

Figure 2. Extracted ion chromatograms of the artemisinin (ART) metabolites obtained from mouse plasma (left) and fermentation broth of C. elegans CICC 40250 (right). (A) monohydroxylation metabolites (M1-M13), (B) dihydroxylation metabolites (M14-M22), (C) deoxyartemisinin (de-ART; M23), (D) deoxygenation followed by hydroxylation metabolites (M24-M31), (E) dihydroartemisinin (DHA; M32) and deoxygenated DHA (M38), (F) hydrogenated DHA (M33-M37), and (G) hydrogenation followed by deoxidization of DHA (M39). 
Table 1. Summary of metabolites of ART detected in mouse plasma (in vivo) and microbial transformation system (in vitro).

\begin{tabular}{|c|c|c|c|c|c|c|c|c|}
\hline \multirow{2}{*}{ No. } & \multirow{2}{*}{ Component } & \multirow{2}{*}{ Formula } & \multirow{2}{*}{$\begin{array}{l}\text { Observed Retention } \\
\text { Time (min) }\end{array}$} & \multicolumn{2}{|c|}{ Plasma (In Vivo) } & \multicolumn{2}{|c|}{ Fermentation Broth (In Vitro) } & \multirow{2}{*}{ Major Fragments } \\
\hline & & & & Observed $m / z$ & Mass Error (mDa) & Observed $\mathrm{m} / \mathrm{z}$ & Mass Error (mDa) & \\
\hline M1 & $\mathrm{ART}+\mathrm{O}$ & $\mathrm{C}_{15} \mathrm{H}_{22} \mathrm{O}_{6}+\mathrm{H}^{+}$ & 2.6 & 299.1487 & -0.2 & - & - & $321,299,337,281,263,253,235,217,207$ \\
\hline M2 & $\mathrm{ART}+\mathrm{O}$ & $\mathrm{C}_{15} \mathrm{H}_{22} \mathrm{O}_{6}+\mathrm{Na}^{+}$ & 2.8 & 321.1301 & -0.5 & 321.1312 & 0.3 & $321,337,299,281,263,253,235,221,207,189$ \\
\hline M3 & $\mathrm{ART}+\mathrm{O}$ & $\mathrm{C}_{15} \mathrm{H}_{22} \mathrm{O}_{6}+\mathrm{Na}^{+}$ & 2.9 & 321.1301 & -0.4 & 321.1309 & 0.1 & $321,337,299,281,263,245,235,221,217,189,175$ \\
\hline M4 & $\mathrm{ART}+\mathrm{O}$ & $\mathrm{C}_{15} \mathrm{H}_{22} \mathrm{O}_{6}+\mathrm{Na}^{+}$ & 3.0 & 321.1304 & -0.4 & 321.1305 & -0.3 & $321,337,299,283,265,235,223,219,207,189,147$ \\
\hline M5 & $\mathrm{ART}+\mathrm{O}$ & $\mathrm{C}_{15} \mathrm{H}_{22} \mathrm{O}_{6}+\mathrm{Na}^{+}$ & 3.5 & 321.1307 & -0.1 & 321.1304 & -0.5 & $321,337,281,263,245,235,217,205,189$ \\
\hline M6 & $\mathrm{ART}+\mathrm{O}$ & $\mathrm{C}_{15} \mathrm{H}_{22} \mathrm{O}_{6}+\mathrm{Na}^{+}$ & 3.7 & 321.1304 & -0.4 & 321.1302 & 1.8 & $321,337,299,281,263,235,221,207,193,189,175$ \\
\hline M7 & $\mathrm{ART}+\mathrm{O}$ & $\mathrm{C}_{15} \mathrm{H}_{22} \mathrm{O}_{6}+\mathrm{Na}^{+}$ & 3.9 & 321.1301 & -0.7 & - & - & $321,299,337,281,253,245,235,223,217,177,149$ \\
\hline M8 & $\mathrm{ART}+\mathrm{O}$ & $\mathrm{C}_{15} \mathrm{H}_{22} \mathrm{O}_{6}+\mathrm{H}^{+}$ & 4.0 & 299.1481 & -0.8 & 321.1301 & -0.8 & $321,337,283,263,253,235,221,207,189,175$ \\
\hline M9 & $\mathrm{ART}+\mathrm{O}$ & $\mathrm{C}_{15} \mathrm{H}_{22} \mathrm{O}_{6}+\mathrm{Na}^{+}$ & 4.2 & - & - & 321.1306 & -0.3 & $321,337,307,267,253,249,235,207,189,175,165$ \\
\hline M10 & $\mathrm{ART}+\mathrm{O}$ & $\mathrm{C}_{15} \mathrm{H}_{22} \mathrm{O}_{6}+\mathrm{Na}^{+}$ & 4.7 & - & - & 321.1301 & -0.7 & $321,299,337,283,261,237,235,219,205,177,165$ \\
\hline M11 & $\mathrm{ART}+\mathrm{O}$ & $\mathrm{C}_{15} \mathrm{H}_{22} \mathrm{O}_{6}+\mathrm{Na}^{+}$ & 4.9 & 337.1038 & -0.6 & 337.1039 & -0.9 & $321,299,337,281,253,235,207,189,179$ \\
\hline M12 & $\mathrm{ART}+\mathrm{O}$ & $\mathrm{C}_{15} \mathrm{H}_{22} \mathrm{O}_{6}+\mathrm{Na}^{+}$ & 5.1 & - & - & 321.1296 & -1.3 & $321,337,299,281,263,253,235,207,189,175,149$ \\
\hline M13 & $\mathrm{ART}+\mathrm{O}$ & $\mathrm{C}_{15} \mathrm{H}_{22} \mathrm{O}_{6}+\mathrm{Na}^{+}$ & 5.8 & - & - & 321.1304 & -0.4 & $321,337,299,281,263,235,217,207,189,175,149$ \\
\hline M14 & $\mathrm{ART}+\mathrm{O} 2$ & $\mathrm{C}_{15} \mathrm{H}_{22} \mathrm{O}_{7}+\mathrm{Na}^{+}$ & 2.0 & 337.1254 & -0.4 & 337.1275 & 1.8 & $337,353,315,297,279,261,251,233,205$ \\
\hline M15 & $\mathrm{ART}+\mathrm{O} 2$ & $\mathrm{C}_{15} \mathrm{H}_{22} \mathrm{O}_{7}+\mathrm{Na}^{+}$ & 2.2 & - & - & 337.1246 & -1.1 & $337,353,277,255,237,219,209,191,163,135$ \\
\hline M16 & $\mathrm{ART}+\mathrm{O} 2$ & $\mathrm{C}_{15} \mathrm{H}_{22} \mathrm{O}_{7}+\mathrm{Na}^{+}$ & 2.2 & 337.1255 & -0.2 & - & - & $337,315,267,252,226,199,176$ \\
\hline M17 & $\mathrm{ART}+\mathrm{O} 2$ & $\mathrm{C}_{15} \mathrm{H}_{22} \mathrm{O}_{7}+\mathrm{Na}^{+}$ & 2.3 & 337.1259 & 0.1 & - & - & $337,297,279,265,247,233,217,201,189$ \\
\hline M18 & $\mathrm{ART}+\mathrm{O} 2$ & $\mathrm{C}_{15} \mathrm{H}_{22} \mathrm{O}_{7}+\mathrm{Na}^{+}$ & 2.4 & - & - & 337.1256 & -0.1 & $337,353,299,299,281,277,263,255$ \\
\hline M19 & $\mathrm{ART}+\mathrm{O} 2$ & $\mathrm{C}_{15} \mathrm{H}_{22} \mathrm{O}_{7}+\mathrm{Na}^{+}$ & 2.5 & - & - & 337.1247 & -1.0 & $337,353,277,253,235,219,209,207,163,135$ \\
\hline M20 & $\mathrm{ART}+\mathrm{O} 2$ & $\mathrm{C}_{15} \mathrm{H}_{22} \mathrm{O}_{7}+\mathrm{Na}^{+}$ & 3.0 & 337.1274 & 1.7 & - & - & $337,321,299,281,279,263,252,235,207,189,147$ \\
\hline M21 & $\mathrm{ART}+\mathrm{O} 2$ & $\mathrm{C}_{15} \mathrm{H}_{22} \mathrm{O}_{7}+\mathrm{Na}^{+}$ & 3.6 & 337.1281 & -0.4 & 337.1068 & -1.1 & $337,353,305,297,279,233,221,177$ \\
\hline M22 & $\mathrm{ART}+\mathrm{O} 2$ & $\mathrm{C}_{15} \mathrm{H}_{22} \mathrm{O}_{7}+\mathrm{Na}^{+}$ & 3.8 & & & 337.1244 & -1.3 & $337,353,315,297,279,261,251,233,205,191,175$ \\
\hline M23 & de-ART & $\mathrm{C}_{15} \mathrm{H}_{22} \mathrm{O}_{4}+\mathrm{H}^{+}$ & 8.3 & 267.1586 & -0.5 & 267.1586 & -0.5 & $289,267,305,249,239,231,221,207,203,193,179$ \\
\hline M24 & de-ART + O & $\mathrm{C}_{15} \mathrm{H}_{22} \mathrm{O}_{5}+\mathrm{Na}^{+}$ & 4.5 & - & - & 305.1355 & -0.5 & $305,321,283,265,247,237,219,201,189$ \\
\hline M25 & $\mathrm{de}-\mathrm{ART}+\mathrm{O}$ & $\mathrm{C}_{15} \mathrm{H}_{22} \mathrm{O}_{5}+\mathrm{H}^{+}$ & 4.9 & 283.1536 & -0.4 & 283.1535 & -0.3 & $283,305,321,265,247,239,191$ \\
\hline M26 & $\mathrm{de}-\mathrm{ART}+\mathrm{O}$ & $\mathrm{C}_{15} \mathrm{H}_{22} \mathrm{O}_{5}+\mathrm{Na}^{+}$ & 5.2 & 283.1531 & -0.9 & 283.1355 & -0.5 & $283,305,265,247,237,219,191,177$ \\
\hline M27 & $\mathrm{de}-\mathrm{ART}+\mathrm{O}$ & $\mathrm{C}_{15} \mathrm{H}_{22} \mathrm{O}_{5}+\mathrm{Na}^{+}$ & 5.4 & - & - & 305.1354 & -0.6 & $305,321,267,247,219,205,177,159$ \\
\hline M28 & de-ART + O & $\mathrm{C}_{15} \mathrm{H}_{22} \mathrm{O}_{5}+\mathrm{Na}^{+}$ & 5.6 & 305.1355 & -0.4 & 305.1358 & -0.1 & $283,305,321,265,247,219,205,177,159$ \\
\hline M29 & de-ART + O & $\mathrm{C}_{15} \mathrm{H}_{22} \mathrm{O}_{5}+\mathrm{Na}^{+}$ & 5.8 & 305.1358 & -0.1 & - & - & $305,283,276,249,239,231,221,207,203,193,179$ \\
\hline M30 & de-ART + O & $\mathrm{C}_{15} \mathrm{H}_{22} \mathrm{O}_{5}+\mathrm{Na}^{+}$ & 6.0 & 305.1353 & -0.8 & 305.1353 & -0.6 & $305,321,265,247,219,205,193,149$ \\
\hline M31 & de-ART + O & $\mathrm{C}_{15} \mathrm{H}_{22} \mathrm{O}_{5}+\mathrm{Na}^{+}$ & 7.2 & - & - & 305.1355 & -0.5 & $305,321,283,247,223,195,167$ \\
\hline M32 & DHA & $\mathrm{C}_{15} \mathrm{H}_{24} \mathrm{O}_{5}+\mathrm{Na}^{+}$ & 7.0 & 307.1505 & -1.1 & - & - & $307,323,267,249,239,231,221,203,163$ \\
\hline M33 & $\mathrm{DHA}+\mathrm{O}$ & $\mathrm{C}_{15} \mathrm{H}_{24} \mathrm{O}_{6}+\mathrm{Na}^{+}$ & 2.2 & - & - & 323.1456 & -1.0 & $323,339,283,265,247,219,189$ \\
\hline M34 & $\mathrm{DHA}+\mathrm{O}$ & $\mathrm{C}_{15} \mathrm{H}_{24} \mathrm{O}_{6}+\mathrm{Na}^{+}$ & 2.5 & - & - & 323.1458 & -0.7 & $323,339,283,265,247,219,191$ \\
\hline M35 & $\mathrm{DHA}+\mathrm{O}$ & $\mathrm{C}_{15} \mathrm{H}_{24} \mathrm{O}_{6}+\mathrm{Na}^{+}$ & 3.1 & - & - & 323.1458 & -0.8 & $323,339,285,267,249,219,191,177$ \\
\hline M36 & $\mathrm{DHA}+\mathrm{O}$ & $\mathrm{C}_{15} \mathrm{H}_{24} \mathrm{O}_{6}+\mathrm{Na}^{+}$ & 3.7 & 323.1449 & -1.6 & 323.1484 & 1.8 & $323,283,265,253,247,237,219,209$ \\
\hline M37 & $\mathrm{DHA}+\mathrm{O}$ & $\mathrm{C}_{15} \mathrm{H}_{24} \mathrm{O}_{6}+\mathrm{Na}^{+}$ & 3.9 & - & - & 323.1456 & -1.0 & $323,285,267,249,239,235,231,221,203$ \\
\hline M38 & DHA-O & $\mathrm{C}_{15} \mathrm{H}_{24} \mathrm{O}_{6}+\mathrm{Na}^{+}$ & 6.6 & - & - & 291.1561 & -0.3 & $291,307,279,269,251,233,223,215,205,179$ \\
\hline M39 & $\mathrm{DHA}-\mathrm{O}+\mathrm{O}$ & $\mathrm{C}_{15} \mathrm{H}_{24} \mathrm{O}_{5}+\mathrm{Na}^{+}$ & 5.8 & 307.1513 & -0.4 & 307.1512 & -0.5 & $307,323,267,249,239,231,221,203,179$ \\
\hline
\end{tabular}

Observed $\mathrm{m} / \mathrm{z}$ of the precursor ions were recorded at low collision energy, and the major fragment ions were recorded at high collision energy. 


\subsubsection{Structural Elucidation of ART Metabolites}

All metabolites were detected within a 16 min chromatographic method. Twenty-two metabolites resulted from hydroxylation, with 13 resulting in monohydroxylated derivatives, $A R T+O$, and nine dihydroxylated derivatives, ART $+2 \mathrm{O}$. Monohydroxylated ART (M1-M13) metabolites were detected between 2.6 to $5.8 \mathrm{~min}$, and exhibited molecular ions at $m / z 305\left([\mathrm{M}+\mathrm{Na}]^{+}\right)$and $m / z 299\left([\mathrm{M}+\mathrm{H}]^{+}\right)$. They showed similar parent ions to ART except with a $16 \mathrm{Da}$ (an oxygen atom) mass shift, as shown in Figure 3A. A fragment with $m / z 281$ resulted from loss of water from the molecular ion at $m / z 299$. High-energy spectra showed that the fragments $m / z 263$ and $m / z 245$ resulted from successive loss of a water from the $m / z 281$ fragment. The fragment ion $m / z 253$ resulted from loss of HCOOH from the $m / z 299$ fragment, and the transition from $m / z 263$ to $m / z 217$ resulted from the same mechanism. In addition, the fragment ion at $m / z 235$ resulted from loss of water from the $m / z 253$ fragment. Fragment $m / z 221$ resulted from loss of $\mathrm{CH}_{3} \mathrm{COOH}$ from the $m / z 281$ fragment.

Metabolites M14-M22 were predicted to be dihydroxylated derivatives, and eluted between 2.0 to $3.8 \mathrm{~min}$. Among these, four metabolites had not been identified in vivo in previous studies. The dihydroxylated ART metabolites showed molecular ions at $m / z 315\left([\mathrm{M}+\mathrm{H}]^{+}\right)$and $m / z 337$ $\left([\mathrm{M}+\mathrm{Na}]^{+}\right)$(Figure 3B). Consistent with monohydroxylation products of ART, they showed a series of product ions resulting from loss of $\mathrm{H}_{2} \mathrm{O}, \mathrm{HCOOH}$, and $\mathrm{CH}_{3} \mathrm{COOH}$. More fragments resulted from loss of water, demonstrating that dihydroxylated ART metabolites had more hydroxyl groups than the monohydroxylated metabolites.

Deoxyartemisinin (M23, de-ART), a known mammalian metabolite of ART, was identified in both plasma and fermentation broth $(\mathrm{Rt}=8.3)$. De-ART showed molecular ions at $m / z 289\left([\mathrm{M}+\mathrm{Na}]^{+}\right)$and $m / z 267\left([\mathrm{M}+\mathrm{H}]^{+}\right)$, and the product ions were consistent with the reference substance (Figure 3C).

Metabolites M24-M31 were proposed to be deoxygenation and hydroxylation metabolites (de-ART + O), which showed molecular ions at $m / z 305\left([\mathrm{M}+\mathrm{Na}]^{+}\right)$and $m / z 283\left([\mathrm{M}+\mathrm{H}]^{+}\right)$. The peaks corresponding to these types of metabolites eluted between 4.5 to $7.8 \mathrm{~min}$. These were isomers of ART, and exhibited the same fragments as ART, such as $m / z 265, m / z 247, m / z 237, m / z 219, m / z 209$, and $m / z$ 191. The fragments $m / z 267,249,239$, and 221 were from addition of $\mathrm{H}_{2}$ to corresponding fragment ions of ART (Figure 3D).

Furthermore, DHA (M32, Rt = $7.0 \mathrm{~min}$ ) was identified in plasma for the first time. DHA exhibited similar molecular ions and fragment ions as the reference substance (Figure 3E).

Hydroxy-DHA metabolites (DHA + O and M33-M37) were identified in both plasma and in the microorganism model. They showed a molecular ion at $m / z 323\left([\mathrm{M}+\mathrm{H}]^{+}\right)$. In high-energy spectra, the fragments $\mathrm{m} / z 285$ and $\mathrm{m} / z 283$ were proposed to represent loss of water with or without addition of $\mathrm{H}_{2}$. The fragments corresponding to $m / z 267,249$, and 231 resulted from successive loss of water, the same mechanism responsible for $m / z 265,247$, and 229. The fragment $m / z 219$ was generated from $m / z 265$ following loss of $\mathrm{HCOOH}$, the same mechanism responsible for transition from $m / z 283$ to $m / z 237$ and from $m / z 285$ to $m / z 339$ (Figure 3F).

Dihydrodeoxyartemisinin (de-DHA and M38) showed molecular ions at $m / z 291\left([\mathrm{M}+\mathrm{Na}]^{+}\right)$ and $269\left([\mathrm{M}+\mathrm{H}]^{+}\right)$, with fragment ions at $m / z 251,233$, and 215 proposed to result from successive loss of water from the molecular ion. In addition, the fragment $m / z 223$ was generated from $\mathrm{m} / \mathrm{z}$ 269 following loss of $\mathrm{HCOOH}$. The fragment $\mathrm{m} / z 205$ resulted from $\mathrm{m} / z 223$ after loss of a water (Figure 3D).

Metabolite M39 was predicted to be hydroxy-dihydrodeoxyartemisinin (de-DHA + O), and was detected at $5.8 \mathrm{~min}$. It was an isomer of DHA, with the same molecular ion at $m / z 307\left([\mathrm{M}+\mathrm{Na}]^{+}\right)$and fragment ions at $m / z 267,249,231$, and 203. In addition, the fragment $m / z 239$ was generated from the molecular ion following loss of $\mathrm{HCOOH}$, and the fragment $m / z 221$ resulted from loss of water from $m / z 239$ (Figure 3G). 

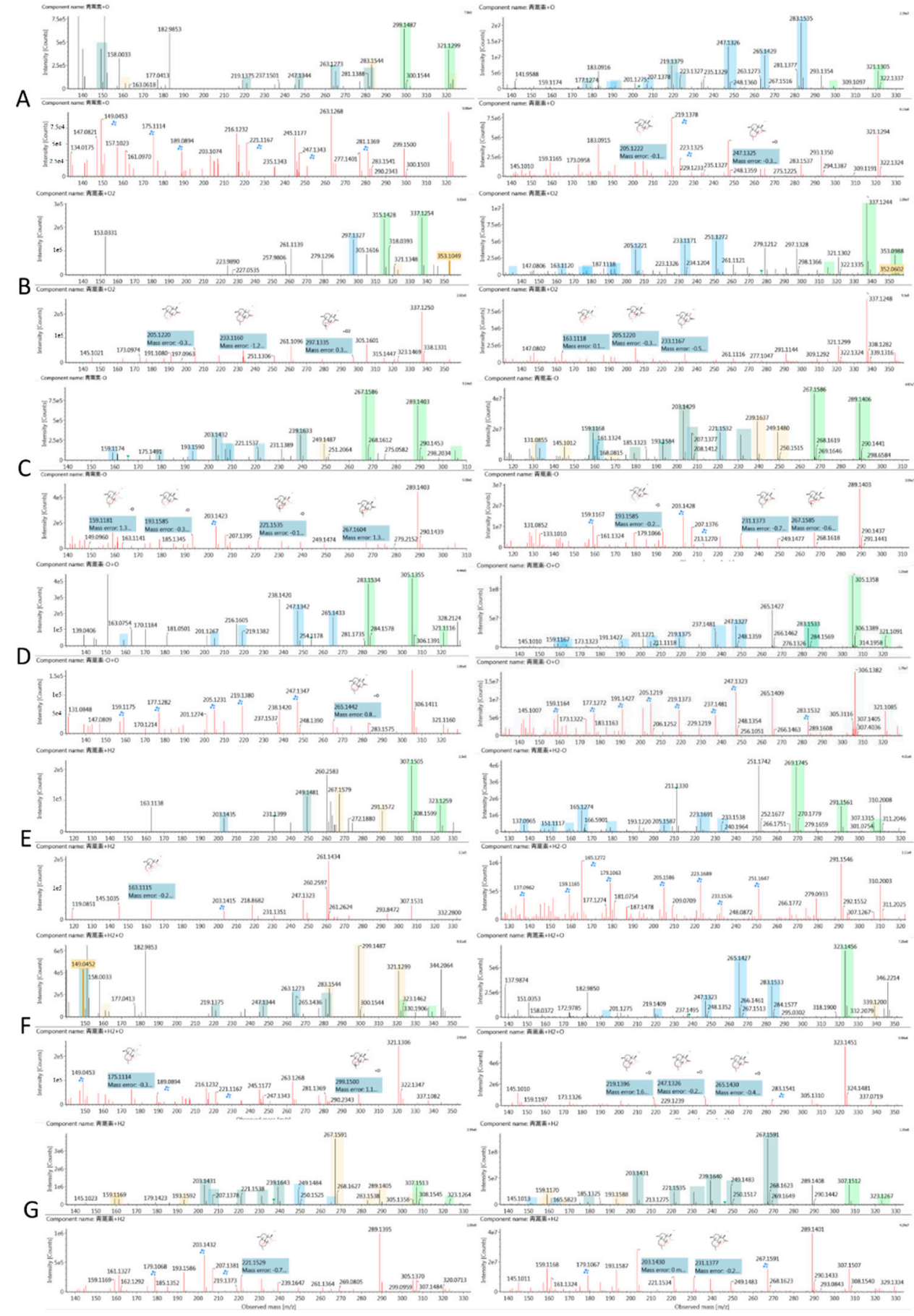

Figure 3. Ultra-performance liquid chromatography-electrospray ionization-quadrupole time-of-flight-mass spectrometry (UPLC-ESI-Q-TOF-MSE) spectra of metabolites in mouse plasma (left) and UPLC-ESI-Q-TOF-MSE spectra of metabolites in microorganisms (right) from the same sample and fragmentation sites in the high energy spectrum. (A) Monohydroxylation metabolite, (B) dihydroxylation metabolite, (C) deoxyartemisinin (de-ART), (D) deoxygenation followed by hydroxylation metabolite, (E) dihydroartemisinin (DHA) and deoxygenated DHA, (F) hydrogenated DHA, and (G) hydrogenation followed by deoxidization of DHA. A blue box behind the low-energy fragment ions shows in-source fragment ions and a green box indicates adduct clusters. 


\subsubsection{Comparison of Results}

To evaluate the capacity of C. elegans CICC 40250 to produce mammalian metabolites, in vitro results were compared with in vivo results. A total of 23 metabolites and 32 metabolites were identified in mouse plasma and the microbial transformation system, respectively. Among these, 16 metabolites were common to both systems. The metabolites generated were seven monohydroxylated derivatives, two dihydroxylated derivatives, deoxyartemisinin, four hydroxylated de-ART derivatives, one hydroxylated DHA derivative, and one hydroxylated deoxy-DHA derivative. In addition, some metabolites were only detected in mouse plasma, including DHA (M32), two monohydroxylated ART derivatives (M1 and M7), three dihydroxylated ART derivatives (M16, M17, and M20), and hydroxylated de-ART (M29). Similarly, some metabolites were only identified in microbial transformation broth. Compared with the in vivo results, more low polarity metabolites of monohydroxylated and dihydroxylated ART, and hydroxylated DHA were detected only in vitro. The proposed metabolic pathways for ART were shown in Figure 4.

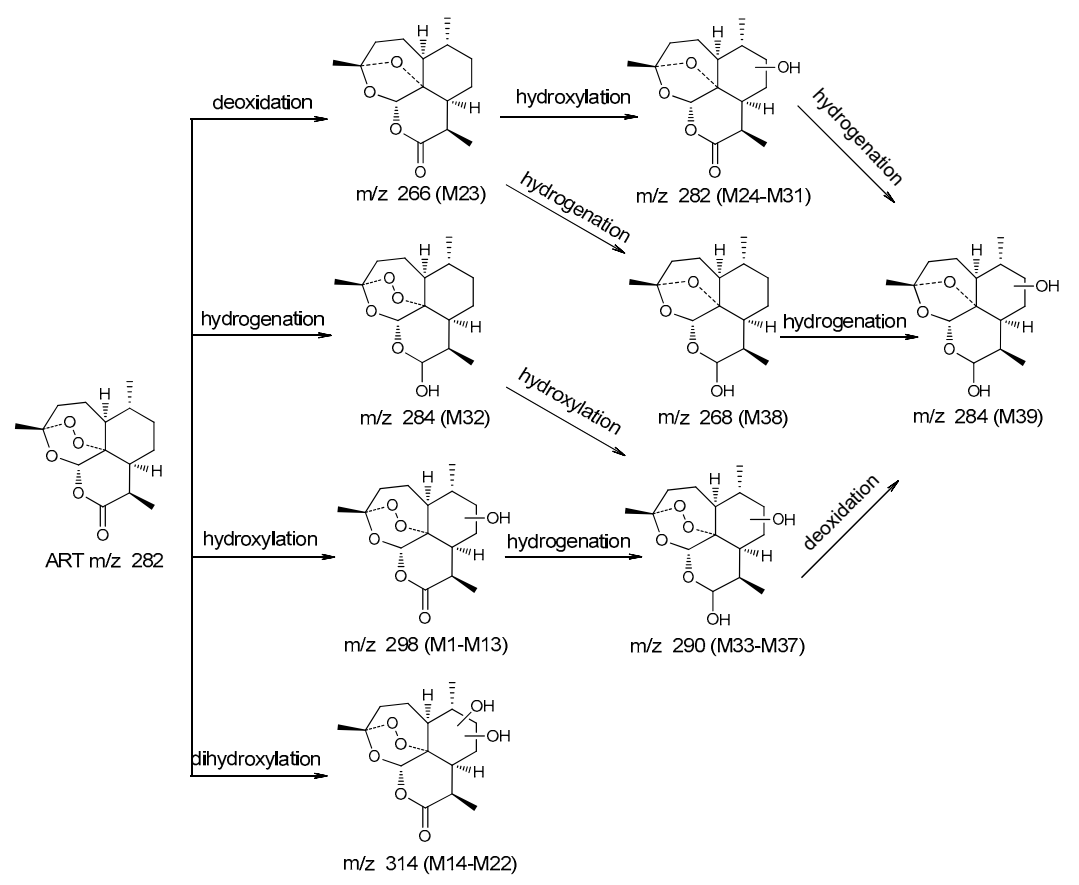

Figure 4. Proposed metabolic pathways of ART.

\section{Discussion}

The metabolism simulation using microbial model has been proved to be effective tool to study the in body process of drugs, especially drugs like ART which have rapid pharmacokinetics [42,43]. Microbial transformation could also provide important route to obtain novel bioactive agents. In our study, a facile microbial model was established for ART metabolism simulation.

Meanwhile, the UPLC-ESI-Q-TOF-MS ${ }^{\mathrm{E}}$ method was successfully employed for identification of the metabolites of ART both in vivo and in vitro. And the combination analysis of microbial transformation of ART with the metabolism in vivo was performed for the first time. This rapid, efficient, and accurate identification method is efficient for screening strains from numerous fungi with ability to metabolize foreign organic substances [44,45]. And the microbial model may allow for identification and isolation of large quantities of metabolites, avoiding use of large numbers of animals. It was believed that in a manner similar to mammalian systems. 


\section{Materials and Methods}

\subsection{Materials and Reagents}

ART and DHA were obtained from the Chongqing Wuling Mountain Pharmaceutical, Kunming Pharmaceutical Group (Chongqing, China, the batch number is MFCD00081057, C00220160402, respectively). The compound had purity $\geq 99 \%$. De-ART was provided by Professor Wang M.Y. (Capital Medical University, Beijing, China). Cunninghamella elegans CICC 40250 was purchased from the China Center of Industrial Culture Collection (Beijing, China). Reagents used were high-performance liquid chromatography (HPLC) grade. Acetonitrile and methanol were purchased from Fisher (Fisher Chemical, Geel, Belgium), while formic acid and ethyl acetate were purchased from Beijing Chemical Works (Beijing, China). Water was prepared using a Milli-Q system operating at 18.2 M $\Omega$ (Millipore, Bedford, MA, USA). All other chemicals used were purchased from Fisher Scientific or Beijing Chemical Works, and were of the highest purity available.

\subsection{Instruments and LC-MS/MS Conditions}

The UPLC-ESI-Q-TOF-MS ${ }^{E}$ system consisted of a Waters ACQUITY I-class UPLC and Xevo G2-XS Q-TOF Mass Spectrometer (Waters, Manchester, UK), equipped with an electrospray ionization (ESI) source (Waters, Manchester, UK). Chromatographic separation was achieved using an Acquity UPLC BEH C 18 (1.0 mm × $150 \mathrm{~mm}, 1.7 \mu \mathrm{m}$, Waters). The mobile phase consisted of solvent A $\left(\mathrm{H}_{2} \mathrm{O}\right.$ containing $0.1 \%$ formic acid $\left.v / v\right)$ and solvent $\mathrm{B}$ (acetonitrile containing $0.1 \%$ formic acid $v / v$ ). The gradient program for plasma samples, which included five segments, was as follows, 5-100\% B from 0 to $15 \mathrm{~min}, 100-5 \%$ B from 15 to $17 \mathrm{~min}$, and a post-run of $3 \mathrm{~min}$ for column equilibration. The flow rate was $0.4 \mathrm{~mL} \mathrm{~min} \mathrm{me}^{-1}$ and the temperature was held at $25{ }^{\circ} \mathrm{C}$ throughout the period of analysis.

The MS was operated in positive ionization mode across a scan range of 50 to $1000 \mathrm{~m} / \mathrm{z}$, with a scan time of $0.2 \mathrm{~s}$. Source parameters: source temperature $120^{\circ} \mathrm{C}$, cone gas $50 \mathrm{~L} / \mathrm{h}$, desolvation temperature $450{ }^{\circ} \mathrm{C}$, and desolvation gas flow $800 \mathrm{~L} / \mathrm{h}$. Argon (99.95\%) was used for collision induced dissociation, and $\mathrm{N}_{2}$ was used as the drift gas. The low collision energy was set to $6 \mathrm{eV}$, and the high collision energy was ramped from 12 to $25 \mathrm{eV}$. $\mathrm{MS}^{\mathrm{E}}$ analysis was conducted using multiple reactions monitoring with positive-ion electrospray ionization. The MS was calibrated weekly by external calibration using the Waters major mix. Leucine enkephalin was used for lock mass correction with $m / z 556.2771$ at an interval of $0.5 \mathrm{~min}$ to ensure robust and accurate mass measurements.

\subsection{MS Data Processing}

All data was collected using MassLynx4.1 (Waters, Manchester, UK) and processing was performed in UNIFI 1.9 (Waters, Manchester, UK). The components were identified in a nontargeted manner by spectral deconvolution in UNIFI 1.9 (Waters, Manchester, UK) by the following 3D peak detection features; low-energy limits of 150 and high-energy limits of 20, isotope clustering, and high-to low energy association within a 0.5 fraction of the chromatographic and drift peak with a mass accuracy of $\pm 2 \mathrm{mDa}$. The maximum number of allowed fragment ions per match was set at 10 .

\subsection{Animal Handling and Sample Preparation}

Male C57 mice (180-200 g) were supplied by Beijing Fang Yuanyuan Farm (Grade II, Certificate No. SCXK 2014-0012). The experimental protocol was approved by the Ethics Committee and conformed to the 'Principles of Laboratory Animal Care'. Mice were fasted for $12 \mathrm{~h}$ before drug administration and for a further $3 \mathrm{~h}$ after dosing. Water was freely available to the mice during the experiments. Mice were given a single oral dose of ART $(100 \mathrm{mg} / \mathrm{kg})$. ART was formulated as a suspension in corn oil. Blood was collected $3 \mathrm{~h}$ after administration by eye removal. Three hours was chosen based on a preliminary study showing that $2.5 \mathrm{~h}$ after oral administration of artemisinin, the blood drug 
concentration decreased rapidly and metabolites increased. The control sample was prepared identical to the test sample except for oral administration.

Plasma and red blood cells were separated by centrifugation (Fersco21, Thermo Fisher, Osterode, Germany) at $860 \times g$ for $15 \mathrm{~min}$, at $4{ }^{\circ} \mathrm{C}$. Plasma samples $(\mathrm{n}=3)$ were loaded onto pretreated solid phase extraction cartridges (Oasis extraction cartridges, Waters, Milford, MA, USA). The cartridges were washed with $1 \mathrm{~mL}$ of water and analytes eluted with $1 \mathrm{~mL}$ of methanol. The methanol fractions were dried by Vacuum freeze concentrator (Xiangyi, Changsha, China). All the samples were reserved at $-80{ }^{\circ} \mathrm{C}$ until reconstituted with $100 \mu \mathrm{L}$ of initial mobile phase and analyzed immediately. Aliquots $(10 \mu \mathrm{L})$ of the reconstituted solutions were injected onto the LC/MS.

\subsection{Culture and Biotransformation Procedures}

The following medium was used in the culture and bioconversion experiments; $20 \mathrm{~g}$ Sabouraud Dextrose Broth (Oxoid), $10 \mathrm{~g}$ peptone (Solarbio, Beijing, China), $15 \mathrm{~g}$ sucrose (Solarbio, Beijing, China), and $1000 \mathrm{~mL}$ deionized water. Cultures were grown on sterile plates.

Fungal mycelia from disks were transferred into $500 \mathrm{~mL}$ shaker flasks containing $100 \mathrm{~mL}$ of medium. After $48 \mathrm{~h}$ of incubation at $28^{\circ} \mathrm{C}$ and $180 \mathrm{rpm}$ on a rotary shaker, $10 \mathrm{~mL}$ cultures containing mycelia were transferred to inoculate $500 \mathrm{~mL}$ Erlenmeyer flasks containing $100 \mathrm{~mL}$ of medium. The inoculated flasks were incubated for $48 \mathrm{~h}$ on rotary shakers at $28^{\circ} \mathrm{C}$ and $180 \mathrm{rpm}$ before addition of ART. ART was dissolved in acetone at a concentration of $25 \mathrm{mg} / \mathrm{mL}$, and $2 \mathrm{~mL}$ of the solution was added into each flask. A total of $50 \mathrm{mg}$ of substrate was used in the biotransformation, and the final concentration of ART in the fermentation system was $0.5 \mathrm{mg} / \mathrm{mL}$. The cultures were incubated under the same conditions for an additional 14 days.

When fermentation was complete, the mycelia and broth were separated by centrifugation $(1180 \times \mathrm{g}, 20 \mathrm{~min})$ and the mycelia were discarded. Aliquots of $10 \mathrm{~mL}$ of the supernatant were extracted with an equal volume of ethyl acetate (EtOAc) three times. The organic phase was collected and evaporated under vacuum, resulting in a brown residue. The residues were dissolved in acetonitrile. The biotransformation sample was obtained after by centrifugation at $13,870 \times g$ for $5 \mathrm{~min}$.

\section{Conclusions}

In conclusion, our results demonstrated the ability of Cunninghamella elegans CICC 40250 to mimic in vivo ART metabolism. This strain was able to produce most types of metabolites found in vivo. The ability of this model to mimic mammalian metabolism, to perform biotransformation reactions, and to produce significant amounts of drug metabolites, suggested that this microbial system represents a suitable alternative for drug metabolism studies. The suitability of this model may eliminate the need to use large quantities of animals in experimental research. Furthermore, ART metabolites were accurately and rapidly identified by UPLC-ESI-Q-TOF-MS ${ }^{\mathrm{E}}$, and DHA was detected and identified as a metabolite of ART in mouse plasma for the first time. This method for screening suitable strains demonstrated the possibility of obtaining valuable metabolites in large quantities in vitro.

Author Contributions: L.Y. conceived the idea for this project, designed, and conducted experiments. Y.M. collected and analyzed the data and wrote the manuscript with contributions from other authors. D.Z. participated in research design and assisted in the data analysis. Y.Z. and X.C. participated in performing the microbial transformation experiments. K.W. and Y.B. assisted in animal experiments. P.S. contributed to the writing.

Funding: This work was supported by emergency management program of national natural science foundation of China (Grant No. 81641002), major science and technology project for 'Significant New Drugs Creation' (Grant No. 2017ZX09101002-002).

Acknowledgments: Thanks to Huimin Gao from the Institute of Chinese Materia Medica, China Academy of Chinese Medical Sciences for critical review of this manuscript. Thanks to Manyuan Wang Capital medical university for supporting reference substance.

Conflicts of Interest: The authors declare no conflict of interest. 


\section{References}

1. Liu, C.Z.; Zhao, Y.; Wang, Y.C. Artemisinin: Current state and perspectives for biotechnological production of an antimalarial drug. Appl. Microbiol. Biotechnol. 2006, 72, 11-20. [CrossRef] [PubMed]

2. Katarzyna, B.; Wanda, B.D. Searching for artemisinin production improvement in plants and microorganisms. Curr. Pharm. Biotechnol. 2011, 12, 1743-1751.

3. World Health Organization. World Malaria Report 2017; World Health Organization: Geneva, Switzerland, 2017; ISBN 978-92-4-156552-3.

4. Shi, C.C.; Li, H.P.; Yang, Y.F.; Hou, L.F. Anti-inflammatory and immunoregulatory functions of artemisinin and its derivatives. Mediat. Inflamm. 2015, 2015, 1-7. [CrossRef]

5. Li, C.C.; Yin, K.; Yang, G. Advance in research on the pharmacological action of the antimalarial artemisinin and its derivates. J. Pathog. Biol. 2016, 11, 185-188.

6. Wang, J.; Zhang, C.-J.; Chia, W.N.; Loh, C.C.Y.; Li, Z.; Lee, Y.M.; He, Y.; Yuan, L.-X.; Lim, T.K.; Liu, M.; et al. Haem-activated promiscuous targeting of artemisinin in Plasmodium falciparum. Nat. Commun. 2015, 6. [CrossRef] [PubMed]

7. Pawluk, S.A.; Wilby, K.J.; Ensom, M.H.H. Pharmacokinetic profile of artemisinin derivatives and companion drugs used in artemisinin-based combination therapies for the treatment of plasmodium falciparum malaria in children. Clin. Pharmacokinet. 2013, 52, 153-167. [CrossRef] [PubMed]

8. Davis, T.M. Pharmacokinetic studies of antimalarials; recent developments. Expert Rev. Clin. Pharmacol. 2016, 9, 341-343. [CrossRef]

9. Gordi, T.; Xie, R.; Huong, N.V. A semiphysiological pharmacokinetic model for artemisinin in healthy subjects incorporating autoinduction of metabolism and saturable first-pass hepatic extraction. Br. J. Clin. Pharmacol. 2005, 59, 189-198. [CrossRef]

10. Feng, Y.L. Establishment of the Microbial Model with the Activity of CYP3A4. Master's Thesis, Shenyang Pharmaceutical University, Shenyang, China, May 2007.

11. Yang, X.W. Establish a Microbial Model with the Activity of Drug-Metabolizing Enzyme CYP2C9. Master's Thesis, Jilin University, Changchun, China, May 2005.

12. Lin, L.; Huang, H.; Zhang, P.; Qi, X.; Zhong, D. Microbial transformation of dextromethorphan by cunninghamella blakesleeana as 3.153. Chem. Pharm. Bull. 2007, 55, 658-661. [CrossRef]

13. Zhang, P.; Lin, L.H.; Huang, H.H.; Xu, H.Y.; Zhong, D.F. Biotransformation of indomethacin by the fungus Cunninghamella blakesleeana. Acta Pharmacol. Sin. 2006, 27, 1097-1102. [CrossRef]

14. Amadio, J.; Gordon, K.; Murphy, C.D. Biotransformation of flurbiprofen by Cunninghamella Species. Appl. Environ. Microb. 2010, 76, 6299-6303. [CrossRef] [PubMed]

15. Zhu, D.Y.; Huang, B.S.; Chen, Z.L.; Yin, M.L.; Yang, Y.M.; Dai, M.L.; Wang, B.D.; Huang, Z.H. Isolation and identification of the metabolite of artemisinin in human. Zhongguo Yao Li Xue Bao 1983, 4, 194-197. [PubMed]

16. Liu, T.; Du, F.; Wan, Y.; Zhu, F.; Xing, J. Rapid identification of phase i and ii metabolites of artemisinin antimalarials using ltq-orbitrap hybrid mass spectrometer in combination with online hydrogen/deuterium exchange technique. J. Mass Spectrom. 2011, 46, 725-733. [CrossRef] [PubMed]

17. Du, F.; Liu, T.; Shen, T.; Zhu, F.; Xing, J. Qualitative-(semi)quantitative data acquisition of artemisinin and its metabolites in rat plasma using an ltq/orbitrap mass spectrometer. J. Mass Spectrom. 2012, 47, $246-252$. [CrossRef] [PubMed]

18. Louw, S.; Njoroge, M.; Chigorimbo-Murefu, N.; Chibale, K. Comparison of electrospray ionisation, atmospheric pressure chemical ionisation and atmospheric pressure photoionisation for the identification of metabolites from labile artemisinin-based anti-malarial drugs using a qtrap ${ }^{\circledR}$ mass spectrometer. Rapid Commun. Mass Spectrom. 2012, 26, 2431-2442. [CrossRef]

19. Svensson, U.S.H.; Mäki-Jouppila, M.; Hoffmann, K.-J.; Ashton, M. Characterisation of the human liver in vitro metabolic pattern of artemisinin and auto-induction in the rat by use of nonlinear mixed effects modelling. Biopharm. Drug Dispos. 2003, 24, 71-85. [CrossRef]

20. Svensson, U.S.H.; Ashton, M. Identification of the human cytochrome P450 enzymes involved in the in vitro metabolism of artemisinin. J. Clin. Pharmacol. 1999, 48, 528-535. [CrossRef]

21. Azerad, R. Microbial models for drug metabolism. Biochem. Eng. Biotechnol. 1999, 63, 169-218. 
22. Prasad, G.S.; Govardhan, P.; Girisham, S. Fungal mediated generation of mammalian metabolites of fenofibrate and enhanced pharmacological activity of the main metabolite fenofibric acid. Drug Metab. Lett. 2014, 8, 88-95. [CrossRef]

23. Hufford, C.D.; Capiton, G.A.; Clark, A.M.; Baker, J.K. Metabolism of imipramine by microorganisms. J. Pharm. Sci. 1981, 70, 151-155. [CrossRef]

24. Rocha, B.A.; Assis, M.D.; Peti, A.P.; Moraes, L.A.; Moreira, F.L.; Lopes, N.P.; Pospíšil, S.; Gates, P.J.; de Oliveira, A.R. In vitro metabolism of monensin A: Microbial and human liver microsomes models. Xenobiotica 2014, 44, 326-335. [CrossRef]

25. Qiao, L.; Zhou, Y.Z.; Qi, X.L.; Lin, L.H.; Chen, H.; Pang, L.Y.; Pei, Y.H. Biotransformation of cinobufagin by Cunninghamella elegans. J. Antibiot. 2007, 60, 261-264. [CrossRef] [PubMed]

26. Parshikov, I.A.; Netrusov, A.I.; Sutherland, J.B. Microbial transformation of antimalarial terpenoids. Biotechnol. Adv. 2012, 30, 1516-1523. [CrossRef] [PubMed]

27. Williamson, J.S.; Parshikov, I.A.; Avery, M.A. Microbial transformations of artemisinin. RPMP Phytochem. Pharmacol. 2007, 17, 115-138. [CrossRef]

28. Liu, J.H.; Chen, Y.G.; Yu, B.Y.; Chen, Y.J. A novel ketone derivative of artemisinin biotransformed by Streptomyces griseus ATCC 13273. Bioorg. Med. Chem. Lett. 2006, 16, 1909-1912. [CrossRef] [PubMed]

29. Parshikov, I.A.; Miriyala, B.; Muraleedharan, K.M.; Illendula, A.; Avery, M.A.; Williamson, J.S. Biocatalysis of the Antimalarial Artemisinin by Mucor ramannianus Strains. Pharm. Biol. 2005, 43, 579-582. [CrossRef]

30. Zhan, J.; Guo, H.; Dai, J.; Zhang, Y.; Guo, D. Microbial transformations of artemisinin by cunninghamella echinulata and aspergillus niger. Tetrahedron Lett. 2002, 43, 4519-4521. [CrossRef]

31. Parshikov, I.A.; Muraleedharan, K.M.; Avery, M.A. Transformation of artemisinin by Cunninghamella elegans. Appl. Microbiol. Biotechnol. 2004, 64, 782-786. [CrossRef]

32. Gaur, R.; Darokar, M.P.; Ajayakumar, P.V.; Shukla, R.S.; Bhakuni, R.S. In vitro antimalarial studies of novel artemisinin biotransformed products and its derivatives. Phytochemistry 2014, 107, 135-140. [CrossRef]

33. Goswami, A.; Saikia, P.P.; Barua, N.C.; Bordoloi, M.; Yadav, A.; Bora, T.C.; Gogoi, B.K.; Saxena, A.K.; Suri, N.; Sharma, M. Bio-transformation of artemisinin using soil microbe: Direct c-acetoxylation of artemisinin at c-9 by penicillium simplissimum. Bioorg. Med. Chem. Lett. 2010, 20, 359-361. [CrossRef]

34. Srivastava, S.; Luqman, S.; Fatima, A.; Darokar, M.P.; Negi, A.S.; Kumar, J.K.; Shanker, K.; Chanotiya, C.S.; Tandon, S.; Khanuja, S.P.S. Biotransformation of artemisinin mediated through fungal strains for obtaining derivatives with novel activities. Sci. Pharm. 2009, 77, 87-95. [CrossRef]

35. Zhan, Y.; Liu, H.; Wu, Y.; Wei, P.; Chen, Z.; Williamson, J.S. Biotransformation of artemisinin by Aspergillus niger. Appl. Microbiol. Biotechnol. 2015, 99, 3443-3446. [CrossRef]

36. Lee, I.-S.; ElSohly, H.N.; Croom, E.M.; Hufford, C.D. Microbial metabolism studies of the antimalarial sesquiterpene artemisinin. J. Nat. Prod. 1989, 52, 337-341. [CrossRef] [PubMed]

37. Parshikov, I.A.; Miriyala, B.; Muraleedharan, K.M.; Avery, M.A.; Williamson, J.S. Microbial transformation of artemisinin to 5-hydroxyartemisinin by eurotium amstelodami and aspergillus niger. J. Ind. Microbiol. Biotechnol. 2006, 33, 349-352. [CrossRef]

38. Zhan, Y.; Wu, Y.; Xu, F.; Bai, Y.; Guan, Y.; Williamson, J.S.; Liu, B. A novel dihydroxylated derivative of artemisinin from microbial transformation. Fitoterapia 2017, 120, 93-97. [CrossRef] [PubMed]

39. Ponnapalli, M.G.; Sura, M.B.; Sudhakar, R.; Govindarajalu, G.; Sijwali, P.S. Biotransformation of Artemisinin to 14-hydroxydeoxyartemisinin: C-14 hydroxylation by Aspergillus flavus. J. Agric. Food Chem. 2018, 66, 10490-10495. [CrossRef] [PubMed]

40. Tu, Y.Y. The discovery of artemisinin (qinghaosu) and gifts from Chinese medicine. Nat. Med. 2011, 17, 1217-1220. [CrossRef]

41. Tu, Y.Y. Artemisinin and Artemisinin Drugs; Chemical Industry Press: Beijing, China, 2009; pp. 34-56. ISBN 978-7-122-00857-2.

42. Meshnick, S.R. Artemisinin: Mechanisms of action, resistance and toxicity. Int. J. Parasitol. 2002, 32, 1655-1660. [CrossRef]

43. Meunier, B.; Robert, A. Heme as trigger and target for trioxane-containing antimalarial drugs. Acc. Chem. Res. 2010, 43, 1444-1451. [CrossRef] [PubMed]

44. Asha, S.; Vidyavathi, M. Cunninghamella-A microbial model for drug metabolism studies-A review. Biotechnol. Adv. 2009, 27, 16-29. [CrossRef] 
45. Karabin, M.; Hudcova, T.; Jelinek, L.; Dostalek, P. Biotransformations and biological activities of hop flavonoids. Biotechnol. Adv. 2015, 33, 1063-1090. [CrossRef] [PubMed]

Sample Availability: Samples of the compounds artemisinin, dihydroartemisinin, and deoxyartemisinin are available from the authors.

(C) 2019 by the authors. Licensee MDPI, Basel, Switzerland. This article is an open access article distributed under the terms and conditions of the Creative Commons Attribution (CC BY) license (http://creativecommons.org/licenses/by/4.0/). 